stone weighing seventy-six grains easily extracted. Blood appeared in the urine; but in fourteen days the boy was well, and was discharged. Later on he came to show himself, when a large fossa in the left lumbar region had formed, which allowed the fist to be pushed into it ; the parts felt flaccid and unresisting.

Siddu Losa, Hindu, aged twenty-two, suffered from severe pain and swelling in the left lumbar region about a year ago, pus and blood were passed in the urine, and a shooting pain down the thigh was experienced; gravel was also passed. The swelling burst and discharged pus by two openings, one of which afterwards closed, the other remained open. When admitted, on February 14th, 1885, the probe could be passed into this opening obliquely, and having been introduced three-quarters of its length, was felt to impinge on a calculus.

The patient having been chloroformed, the fistulous track was opened up on a director, the incision being two inches in length, but the finger had to be pushed in up to the hilt before the stone could be quite bared; it was then loosened with the nail, which occasioned a good deal of bleeding. Forceps were then introduced and an oval calculus weighing ninety-six grains extracted. For two or three days the urine was bloody and the temperature rose to $101^{\circ}$, and there was slight purulent discharge from the wound. These symptoms subsided, and the patient was discharged well on February 20th. Contraction of the tissues in the lumbar region is evidently taking place and a fossa is forming in that region.

Remarks by Mr. HATCH.-Few cases of stone in the kidney occurring in this country have, as far as I am aware, been placed on record. There was no difficulty in diagnosis, as a sinus was present in both cases.

\section{A CASE OF OBLITERATIVE ARTERITIS; OPERATIONS;} TETANUS ; TRANSFUSION ; DEATH ; REMARKS.

(Under the care of Surgeon HATCH, M.B.)

Ismail $\mathrm{K}$ - aged sixteen, a cultivator, noticed during the last rains of 1884 that the little toe of his right foot became blackened, ulcerated, and dropped off. He attributed this to exposure to damp while working in rice fields. Subsequently the other toes of that foot became similarly affected, and separated from the metatarsal bones. There was no history of any previous disease.

On admission, Feb. 3rd, 1885, he was found to be wretchedly emaciated; the greater part of the right foot was blackened, the metatarsal bones protruding nearly their whole length from the soft parts; there was a most offensive odour, and the patient was weak in the extreme; pulse very weak, and pulsation in tibials doubtful.

On the 4th amputation was performed. There was no hæmorrhage from the cut vessels, and they were evidently closed, but, as in a previous case, the stump had done fairly well, notwithstanding the apparently bloodless condition. The flaps were brought together and quinine and woodwool dressings applied.

The patient was much relieved by the operation, but on the 9th the temperature rose, and severe pain was felt again in the leg. The dressings were removed and the leg was found to be cold and blackened. Amputation was immediately performed above the knee. The same evening, from the pinched appearance of the face and slight stiffness of the jaw, it was evident that tetanus had set in. Next day he lay very quiet; pulse thready; trismus the same; vomiting constant. $\mathrm{He}$ lingered on in this state, now better now worse, for some days, but the spasms of the muscles of the legs gradually became very troublesome, not violent, but preventing the patient from moving or even speaking. The stump was dressed, and though anæmic in appearance was otherwise healthy. Chloral had no effect on the tetanic symptoms, hough given in twenty-five grain doses every four hours. The temperature remained steady, between $99^{\circ}$ in the morning and $101^{\circ}$ in the evening. It was then decided to try transfusion of blood; this was done with the consent of the patient. The skin at the bend of the right elbow having been rendered partially anæsthetic by cocaine injection, the vein was opened. At the same time an assistant killed a small goat. Blood from the carotids was received in a warm vessel and well whipped; it was then filtered and kept warm in a water bath. The nozzle of Aveling's apparatus having been introduced into the vein, six ounces of blood were slowly injected by a syringe fitted on to the nozzle. The effect on the patient was to rouse him from his drowsy state; the eyes became glistening and distended, and in a short time the skin was covered with perspiration. On removal to his ward, he slept for some hours. He looked better next day, his voice was also stronger; but, owing to spasm of the abdominal muscles, great difficulty in expectoration was. experienced, and his transitory improvement was followed by death on the night of the 22nd at 10 P.M.

Remarks by Mr. HaTcH.-For some reason or other, possibly the low state of vitality induced by insufficient nourishment, obliterative arteritis followed by dry gangrene is not uncommon amongst the poor of Bombay. The preceding: case is a type of several 1 have seen occurring in young. subjects with no history of any previous disease. Operation has been generally successful, but in this and in another case I saw under the charge of Dr. Gray of this hospital, amputation was probably not sufficiently high, as gangrene. of the stump afterwards took place.

\section{atedical Societies.}

\section{EPIDEMIOLOGICAL SOCIETY OF LONDON.}

\section{A MEEting of the above Society was held on June 10th} Dr. Norman Chevers, C.I.E., President, in the chair.

Mr. E. Chadwick, C.B., read a paper on Ventilation with Air from Superior Layers in place of Inferior Layers. He said his attention was early directed to instances of layers or strata of air of malarious influence, and referred to. instances where those who were obliged to live within or beneath such layers suffered from epidemic visitations, while those dwelling on levels above them escaped. The general effect of land drainage had been to reduce mists and even to remove them, and in such instances had reduced the plague of midges in England, of mosquitoes in Algeria, and ague in the Fen districts of Lincolnshire. Dr. Niell Arnott had suggested drawing air from a height above the common and mist layers, and distributing it into houses by engine power or as gas is distributed; the principle was worthy of consideration in the construction of hospitals. The admirable methods of internal ventilation in some hospitals of Paris and in England really introduced air that was positively bad, because it was drawn from lower couches and was common street air polluted by street and sewer emanations; were the air drawn from superior and pure layers, there would be no need for washing the air of surgical wards before operations. Of the two systems of ventilation, one of "propulsion" or driving in the air, the other of "aspiration" or of drawing it out by suction, the principle of the latter was peculiarly adapted to drawing in the air from the superior layer, obtained from two, three, four, or five hundred feet, or whatever height might be desired. The principle was also applicable for securing sleep in India and southern cities, free from the plague of mosquitoes, since these fed exclusively in the animalised gases diffused amongst the lower layers of air. The engine power required for this service would be less than that for ventilation by punkahs. The temperature of the superior air might be easily raised, as at Lariboisière Hospital, by hot water in its downward course, or on its. admission into the building; it could easily be lowered, if necessary, by being passed over surfaces cooled down by evaporation. The expense would be less than that of warming edifices by the ordinary method. Common absorbent brick ought not to be used in the construction of towers for the obtaining of pure air, but non-absorbent concrete would appear to be the most eligible material ; the requisite heights of the towers would have to be ascertained experimentally.

Inspector-General ROBERT LAwson drew attention to the subject of Outbreaks of Cholera in Ships carrying coolies from Calcutta, and showed the periods of these occurrences and the ships' positions at the time. He said that when Mr. Bolton G. Corney, colonial surgeon, Fiji, was in this country last autumn he mentioned that cholera had appeared in some ships carrying coolies from Calcutta to Fiji, and that some ten cases of cholera had occurred in 1880 among coolies who had been in the colony about a year, four of which had proved fatal. Since his return to Fiji Mr. Corney has sent home notes of four ships that suffered from cholera during their voyage from Calcutta; each vessel had about 500 coolies besides its crew. Of these, the Leonidas sailer? 